in vivo $35: 603-609(2021)$

doi:10.21873/invivo.12297

\title{
Low MLL2 Protein Expression Is Associated With Fibrosis in Early Stage Gastric Cancer
}

\author{
SATOE NUMAKURA and HIROSHI UOZAKI \\ Department of Pathology, Teikyo University School of Medicine, Tokyo, Japan
}

\begin{abstract}
Background/Aim: Myeloid/lymphoid or mixed lineage leukemia 2 (MLL2) gene is mutated in gastric cancer, with most resulting in inactivated proteins. In this study, we examined the expression of MLL2 protein in gastric cancers. Patients and Methods: The expression of MLL2 protein in cancer cell nuclei was studied by immunohistochemistry in tissue microarrays of 529 human gastric cancers. MLL2 expression was classified into low and high expression from the point of zygosity, and its relationships with mismatch repair protein expression and clinicopathological features were examined. Results: Low expression of MLL2 was associated with younger age, MSH6, and early cancers. MLL2-low pTla cancers were associated with fibrosis, especially ulcer scars, and in $62.5 \%$ of them there was no direct contact between carcinoma and fibrosis. Conclusion: There is potentially an association between low expression of MLL2 protein and gastric malignancy from chronic fibrosis.
\end{abstract}

Myeloid/lymphoid or mixed lineage leukemia 2 (MLL2), also called KMT2D, MLL4 in mice, is mutated in various types of tumors (1-3), including gastric cancer (4-6). The frequency of MLL2 gene mutations in gastric cancer detected using nextgeneration sequencing has been reported in limited cases; $15.4 \%$ of advanced cancers (4), $6.9 \%$ of advanced cancers and metastasis (5), and $19.1 \%$ of mucinous carcinoma (6). Reported MLL2 gene mutations in gastric cancers are frameshift mutations, nonsense mutations, indel mutations, amino acid deletions, or base substitutions, which result in inactivated protein (4-6). There is also a study that examined the clinicopathological characteristics of the over-expression of

This article is freely accessible online.

Correspondence to: Hiroshi Uozaki, Department of Pathology, Teikyo University School of Medicine, 2-11-1 Kaga, Itabashi-ku, Tokyo 1738605, Japan. Tel: +81 339643498, e-mail: uozaki@med.teikyo-u.ac.jp

Key Words: Gastric cancer, MLL2 (KMT2D), fibrosis, ulcer scar, immunohistochemistry.
MLL2 protein in gastric cancer using immunohistochemistry (7). MLL2 knockdown cells exhibit genomic instability in vitro $(1,2)$. Genomic instability plays a role in gastric carcinogenesis (8) and results from a defect in the surveillance mechanisms maintaining genomic integrity, which include microsatellite instability, chromosome instability, epigenetics, and an increased frequency of base pair mutations $(9,10)$. The mechanisms underlying genomic instability induced by the knockdown of MLL2 include transcriptional stress during early replication cycles in relation to RNA polymerase II $(1,11)$, chromosomal instability (1), and epigenetic changes in oncogenes based on its function as a H3K4 methyltransferase $(2,12)$. In the present study, we focused on the role of the low expression of MLL2 protein in both advanced and early stage gastric cancers and examined their clinicopathological features.

\section{Patients and Methods}

Tissue samples. The present study was approved by the Ethics Committee of the Teikyo University School of Medicine (No. 18134, 2 November 2018). In total, 529 primary gastric cancers surgically resected from 509 patients between 2000 and 2011 were obtained from the archives of the Department of Pathology, Teikyo University Hospital. Seven cases of advanced cancers had received neo-adjuvant therapy. All clinicopathological parameters were obtained from the electronic medical records, including patient age and gender, tumor size, tumor stage, histological classification, Lauren's classification, lymphatic infiltration, venous infiltration and lymph node metastasis. Tumor stage was divided into early (pT1a or pT1b) and advanced (pT2-pT4) based on the T stage in TNM classification according to the eighth edition of the Union for International Cancer Control (UICC) guidelines. Epstein-Barr virus (EBV) infection was evaluated by Epstein-Barr virus-encoded small RNAs (EBER) in situ hybridization. Clinicopathological information on patients and cores is summarized in Table I.

Immunohistochemistry of tissue microarrays. The tissue microarray set of gastric cancers used herein was constructed according to our previous study (13). Briefly, cylindrical tissue cores of $2 \mathrm{~mm}$ in size from formalin-fixed, paraffin-embedded (FFPE) blocks were arrayed using the manual device KIN-1 (Azumaya, Tokyo, Japan). Two representative cores were taken from each tissue block, and the resulting tissue array blocks were sectioned at a thickness of $4 \mu \mathrm{m}$, placed on slides, and stained with the following antibodies to human 
Table I. Summary of the patients and gastric cancers.

\begin{tabular}{lc}
\hline Patient number & 509 \\
Tumor number & 529 \\
Age (years) & $68.1 \pm 10.8^{*}$ \\
Gender (Male/Female) & $382 / 147$ \\
Size (mm) & $54.7 \pm 50.3^{*}$ \\
Tumor stage (Early/Advanced) $\dagger$ & $209 / 320$ \\
Lauren's classification (Intestinal/Diffuse) & $295 / 233$ \\
Lymphatic infiltration (Negative/Positive) & $247 / 281$ \\
Venous infiltration (Negative/Positive) & $252 / 276$ \\
Lymph node metastasis (Negative/Positive) & $258 / 267$ \\
EBV (Negative/Positive) & $471 / 36$ \\
MLL2 (Low/High) & $82 / 447$ \\
MLH1 (Low/High) & $77 / 448$ \\
PMS2 (Low/High) & $82 / 432$ \\
MSH2 (Low/High) & $58 / 455$ \\
MSH6 (Low/High) & $34 / 482$ \\
Fibrosis (pT1a) (Negative/Positive) & $77 / 51$ \\
Ulcer scar (pT1a) (Negative/Positive) & $89 / 39$ \\
\hline
\end{tabular}

* Mean \pm standard deviation; †Early means pT1a or pT1b in TNM classification.

proteins: MLL2 (HPA035977, 1:100, Atlas Antibodies, Stockholm, Sweden), MLH1 (G168-15, 1:50, Biocare Medical, Concord, CA, USA), PMS2 (EP51, ready-to-use, Dako, Agilent Technologies, Glostrup, Denmark), MSH2 (FE11, ready-to-use, Dako, Agilent Technologies), and MSH6 (EP49, ready-to-use, Dako, Agilent Technologies). Antigen retrieval was performed via water bath heating for MLL2, PMS2, MSH2 and MSH6 or autoclave for MLH1 in retrieval buffers ( $\mathrm{pH} 6$ for MLL2, pH9 for MLH1, PMS2, MSH2 and MSH6). For visualization, we used the EnVision FLEX system (Agilent, Santa Clara, CA, USA). All proteins were localized in the nucleus and their expression in cancer cells was assessed. The intensity of MLL2 expression within cancer tissue was homogenous or heterogenous and showed the following 6 patterns (Figure 1): negative (score 0 ), mixture of negative and low positive (score 1), low positive (score 2), mixture of low positive and positive (score 3 ), positive (score 4) and mixture of positive and negative (score 5). The intensity of MLL2 protein in benign gastric glandular cells was low positive. Homozygous and heterozygous mutations of MLL2 gene result in the loss-of-function phenotype. MLL2 mRNA was absent in homozygous mutations and about $50 \%$ decreased in heterozygous mutations (14); therefore, under the assumption that mRNA expression and protein expression correlate, we defined scores 0 and 1 as low expression and scores 2-5 as high expression. Based on a previously reported classification (15), the expression of mismatch repair proteins (MLH1, PMS2, MSH2, and MSH6) was divided into five scores according to the nuclear positivity rate of carcinoma cells; score $0(0 \%)$, score $1(0-10 \%)$, score $2(10-30 \%)$, score $3(30-70 \%)$, and score 4 (70-100\%). Scores 0 and 1 were classified as low expression and scores 2-4 as high expression. Scoring was performed by two pathologists who reached a consensus through discussions in cases of discordance. Only cores in which carcinoma occupied more than half of the area were evaluated; therefore, 529 cores were ultimately assessed.

Histological evaluation of submucosal fibrosis. We evaluated fibrosis in cancers that occupied the mucosal layer only (pT1a). We reviewed
Table II. MLL2 protein expression and clinicopathological features.

\begin{tabular}{|c|c|c|c|c|}
\hline & & \multicolumn{2}{|c|}{ MLL2 } & \multirow[b]{2}{*}{$p$-Value } \\
\hline & & Low $(\%)$ & High (\%) & \\
\hline \multirow[t]{2}{*}{ Gender } & Male & $59(72.0)$ & $323(72.3)$ & \\
\hline & Female & $23(28.0)$ & $124(27.7)$ & 1 \\
\hline Age & & $64.4 \pm 13.9$ & $68.8 \pm 10.0$ & 0.0007 \\
\hline Size (mm) & & $53.7 \pm 43.2$ & $54.9 \pm 51.5$ & 0.841 \\
\hline \multirow[t]{2}{*}{ Stage } & Early & $42(51.2)$ & $167(37.4)$ & \\
\hline & Advanced & $40(48.8)$ & $280(62.6)$ & 0.0199 \\
\hline \multirow{2}{*}{$\begin{array}{l}\text { Venous } \\
\text { infiltration }\end{array}$} & Negative & $46(56.1)$ & $206(46.2)$ & \\
\hline & Positive & $36(43.9)$ & $240(53.8)$ & 0.118 \\
\hline \multirow{2}{*}{$\begin{array}{l}\text { Lymphatic } \\
\text { infiltration }\end{array}$} & Negative & $41(50.0)$ & $206(46.2)$ & \\
\hline & Positive & $41(50.0)$ & $240(53.8)$ & 0.549 \\
\hline \multirow{2}{*}{$\begin{array}{l}\text { Lymph node } \\
\text { metastasis }\end{array}$} & Negative & $42(51.9)$ & $216(48.6)$ & \\
\hline & Positive & $39(48.1)$ & $228(51.4)$ & 0.63 \\
\hline \multirow{4}{*}{$\begin{array}{l}\text { Lauren's } \\
\text { classification } \\
\text { EBV status }\end{array}$} & Intestinal & $44(53.7)$ & $251(56.3)$ & \\
\hline & Diffuse & $38(46.3)$ & $195(43.7)$ & 0.717 \\
\hline & Negative & 74 (92.5) & $397(93.0)$ & \\
\hline & Positive & $6(7.5)$ & $30(7.0)$ & 0.815 \\
\hline \multirow[t]{2}{*}{ MLH1 } & Low & $16(19.5)$ & $61(13.8)$ & \\
\hline & High & $66(80.5)$ & $382(86.2)$ & 0.177 \\
\hline \multirow[t]{2}{*}{ PMS2 } & Low & 15 (18.5) & $67(15.5)$ & \\
\hline & High & $66(81.5)$ & $366(84.5)$ & 0.509 \\
\hline \multirow[t]{2}{*}{ MSH2 } & Low & 11 (13.6) & 47 (10.9) & \\
\hline & High & $70(86.4)$ & $385(89.1)$ & 0.45 \\
\hline \multirow[t]{2}{*}{ MSH6 } & Low & 14 (17.3) & $20(4.6)$ & \\
\hline & High & $67(82.7)$ & 415 (95.4) & 0.0002 \\
\hline \multirow[t]{2}{*}{ Fibrosis (pT1a) } & Negative & $8(29.6)$ & $58(73.4)$ & \\
\hline & Positive & $19(70.4)$ & 21 (26.6) & $<0.0001$ \\
\hline \multirow{2}{*}{$\begin{array}{l}\text { Ulcer scar } \\
\text { (pT1a) }\end{array}$} & Negative & $11(40.7)$ & $63(79.7)$ & \\
\hline & Positive & $16(59.3)$ & $16(20.3)$ & 0.0004 \\
\hline
\end{tabular}

all Hematoxylin-Eosin (HE) slides of corresponding surgical specimens and examined whether submucosal fibrosis was present under cancer tissue. In total, 128 cancers were evaluated. The following four patterns were observed (Figure 2A-D): no fibers, scattered fibers, loosely connected fibers, and dense fibers. We defined the latter two patterns (Figure 2C and D) as fibrosis. Fibrosis with a ruptured muscularis mucosae was defined as an ulcer scar (16) (Figure $3 \mathrm{~A})$. We classified pT1a cancers with ulcer scars into the following five types based on the criteria proposed by Japanese pathologists and surgeons (17) (Figure 3B-F): Type A includes cancers with a mucosal upper part of carcinoma and lower part of benign gastric glands. Type $\mathrm{B}$ is carcinoma occupying all mucosal layers. In Type C, ulcers form within carcinoma. In Types D and $\mathrm{E}$, a benign regenerative mucosa exists between mucosal carcinoma (carcinoma only in the upper layer of the mucosa: Type D, carcinoma in all mucosal layers: Type E). As potential factors affecting fibrosis, we examined the findings of previous biopsies of cancer and histological subtypes [poorly differentiated carcinoma ("por") and/or signet ring cell carcinoma ("sig")] by referring to medical records and specimens.

Statistical analysis. We used the chi-squared test or Fisher's exact test for categorical variables and $2 \times 2$ tables were employed to calculate odds ratios. We used a logistic regression in a multivariate 

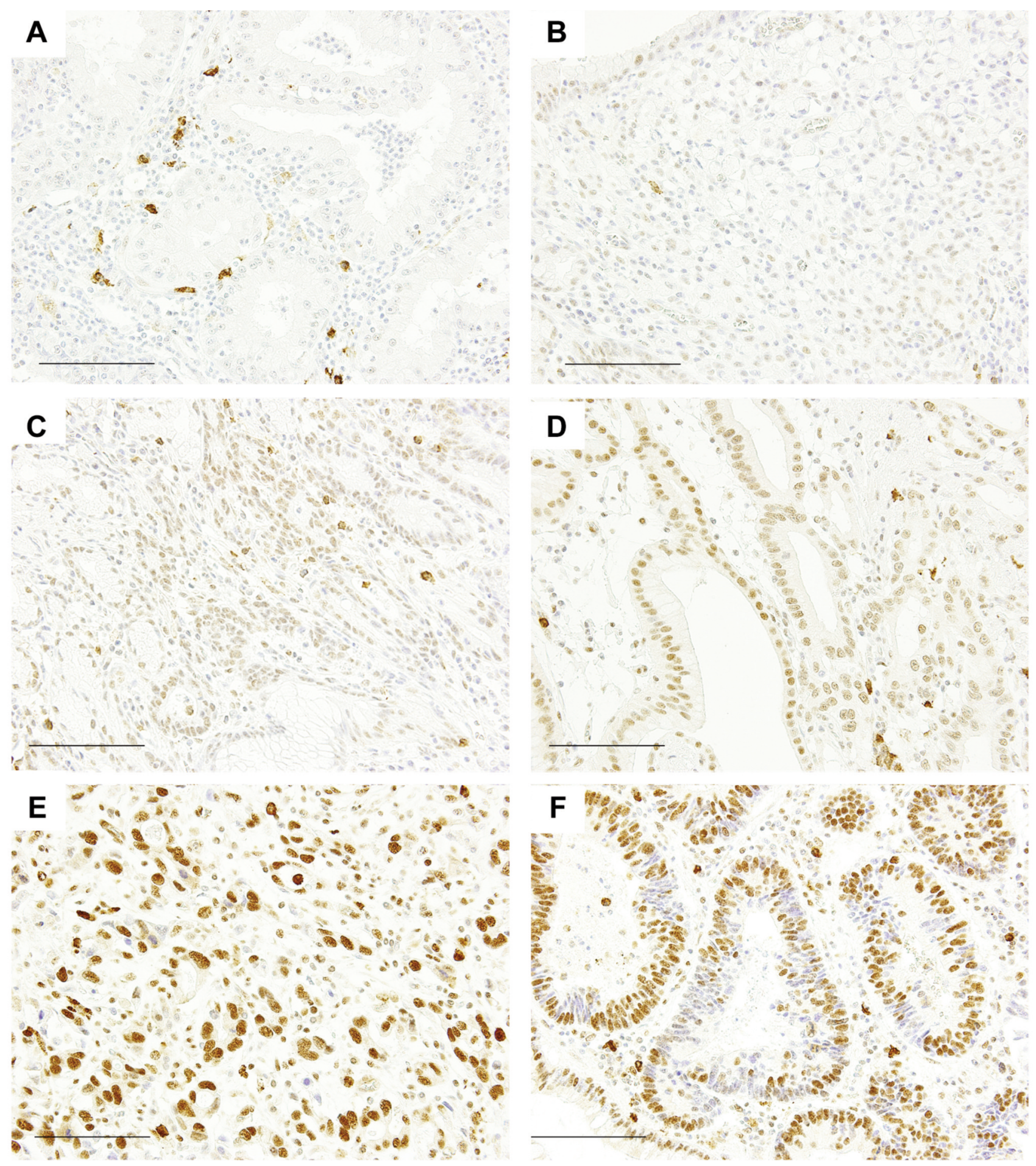

Figure 1. MLL2 immunohistochemistry and scoring. (A) Score 0 (negative). (B) Score 1 (mixture of negative and low positive). (C) Score 2 (low positive). (D) Score 3 (mixture of low positive and positive). (E) Score 4 (positive). (F) Score 5 (mixture of positive and negative). We defined scores 0 and 1 as low expression. Scale bar $=100 \mu \mathrm{m}$.

analysis. The Student's $t$-test was performed for comparisons between two samples with continuous variables. Pearson's productmoment correlation test was conducted to assess relationships between two variables. We used the Kaplan-Meier method and Logrank test in a univariate survival analysis. $p$-Values of less than 0.05 were considered significant. 

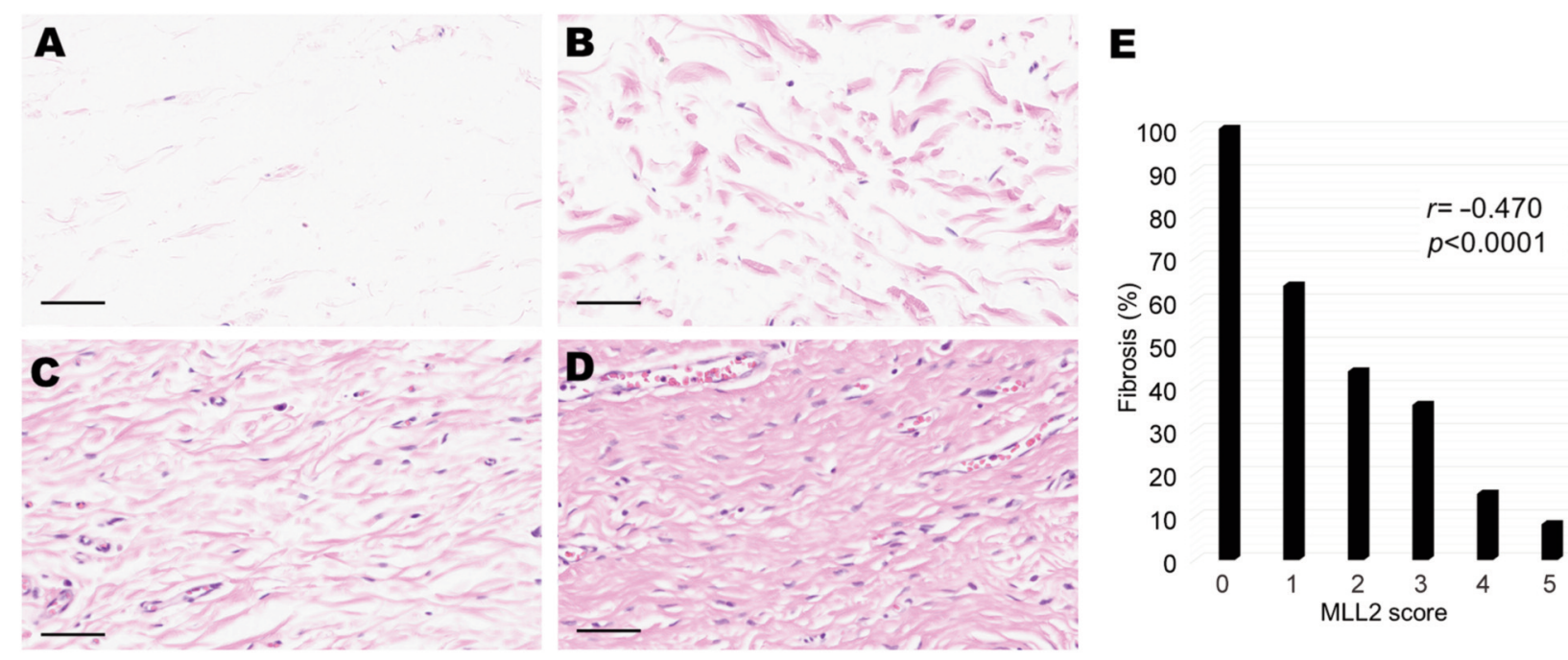

Figure 2. Submucosal fiber patterns (Hematoxylin-eosin stain, scale bar=50 $\mu \mathrm{m}$ ) and the correlation between MLL2 scores and fibrosis. (A) No fibers. (B) Scattered fibers. (C) Loosely connected fibers. (D) Dense fibers. Submucosal fibrosis is observed in (C) and (D). (E) MLL2 scores and the proportion of fibrosis in pTla cancers; score 0 [5/5 cases (100\%)], score 1 [14/22 cases (63.6\%)], score 2 [7/16 cases (43.8\%)], score 3 [9/25 cases (36\%)], score 4 [4/26 cases (15.4\%)], and score 5 [1/12 cases $(8.3 \%)]$.

\section{Results}

Clinicopathological characteristics of low expression MLL2 gastric cancers. We examined nuclear MLL2 protein expression in the cancer cells of gastric cancer tissues. MLL2 expression was significantly decreased in $15.5 \%$ (82/529 cases) of all examined cancers (Table I), $20.1 \%$ (42/209 cases) of early cancers, and $12.5 \%$ (40/320 cases) of advanced cancers. The low expression of MLL2 was associated with a younger age (the Student's $t$-test, $p=0.0007 ; 95 \% \mathrm{CI}=-6.91-1.86$ ), early cancers (Fisher's exact test, $p=0.0199$; odds ratio $1.76,95 \% \mathrm{CI}=1.07-2.91)$, and the low expression of MSH6 (Fisher's exact test, $p=0.0002$; odds ratio 4.32, 95\% CI=1.92-9.49) (Table II). The relationship between MLL2 and MSH6 was observed in advanced cancers (Fischer's exact test, $p<0.0001$; odds ratio $7.91,95 \% \mathrm{CI}=2.76-22.49$ ), but not in early cancers (Fisher's exact test, $p=0.307$; odds ratio 1.82 , $95 \% \mathrm{CI}=0.39-6.97)$. No significant differences were noted between MLL2 expression and overall survival (the Logrank test, $p=0.72$ ).

Low expression of MLL2 and submucosal fibrosis. Based on the relationship observed between low expression of MLL2 and early stage cancers, we focused on intra-mucosal gastric cancers (pT1a) and investigated whether fibrosis was present under the cancer tissue (Figure 2A-D). Low expression of MLL2 was associated with fibrosis in univariate (Fisher's exact test, $p<0.0001$; odds ratio 6.42, $95 \% \mathrm{CI}=2.29-19.73$ ) (Table II) and multivariate analyses (logistic regression, $p=0.0017$; odds ratio 5.91, 95\% CI=1.95-17.9) (Table III). A negative correlation was noted between MLL2 scores and fibrosis (Pearson's product-moment correlation test, $r=-0.470, p<0.0001$, $95 \% \mathrm{CI}=-0.61--0.31$ ) (Figure 2E).

We defined fibrosis with a ruptured muscularis mucosae as an "ulcer scar" (16) (Figure 3A). Low expression of MLL2 in pT1a cancer was also associated with ulcer scars in univariate (Fisher's exact test, $p=0.0004$; odds ratio $=5.61$, 95\% CI=2.01-16.39) (Table II) and multivariate analyses (Logistic regression, $p=0.0019$; odds ratio 5.14, 95\% CI=1.83-14.5) (Table II). We classified pT1a cancers with ulcer scars into 5 types. Type A includes cancers with a mucosal upper part of carcinoma and lower part of benign gastric glands (Figure 3B). Type B is carcinoma occupying all mucosal layers (Figure 3C). In Type $C$, ulcers form within carcinoma (Figure 3D). In Type D and type E, a benign regenerative mucosa exists between mucosal carcinoma [carcinoma only in the upper layer of the mucosa: Type D (Figure 3E), carcinoma in all mucosal layers: Type E (Figure $3 \mathrm{~F})$ ]. In all pT1a cancers with ulcer scar, type A were $33.3 \%$ (13/39 cases), type B were $23.1 \%$ (9/39 cases), type C were $2.6 \%$ (1/39 cases), type D were $28.2 \%$ (11/39 cases), and type $\mathrm{E}$ were $12.8 \%$ (5/39 cases). In the MLL2 low expression group, $31.3 \%$ (5/16 cases) were type A, $37.5 \%$ (6/16 cases) were type B and $31.3 \%$ (5/16 cases) were type D. No case was categorized into type $\mathrm{C}$ or type $\mathrm{E}$ in the MLL2 low expression, although no significant differences were observed between ulcer scar types and MLL2 expression (Fisher's exact test, $p=0.126$ ). 

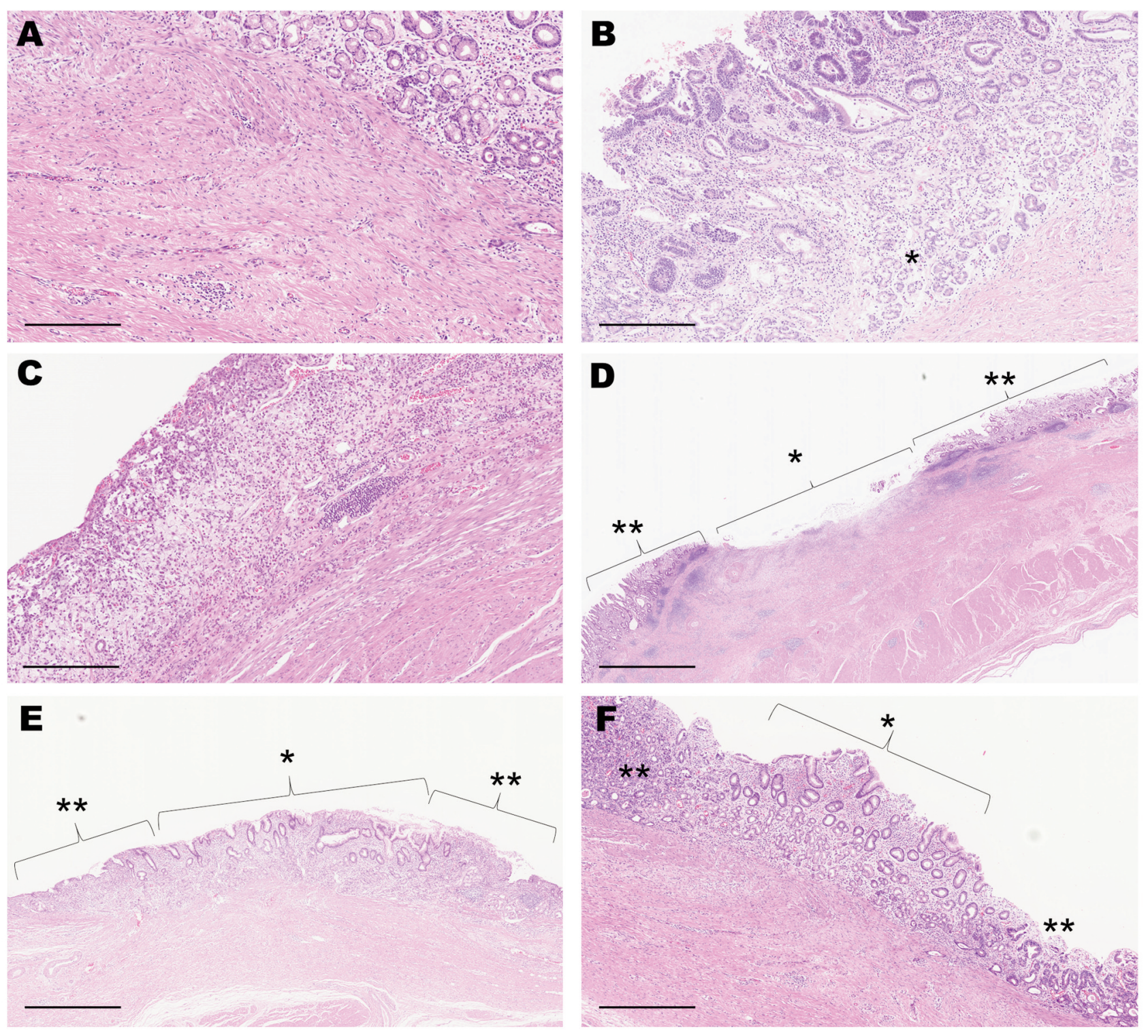

Figure 3. pTla cancers with ulcer scars (Hematoxylin-eosin stain). (A) Fibrosis with a ruptured muscularis mucosae (scale bar=250 $\mu \mathrm{m})$. (B) Type A: Carcinoma in the mucosal upper layer and benign gastric glands $\left(^{*}\right)$ in the lower layer (scale bar $\left.=300 \mu m\right)$. (C) Type B: carcinoma occupying

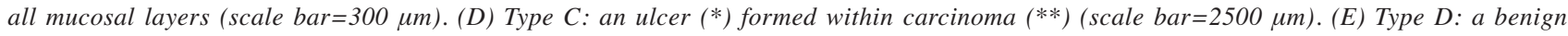
regenerative mucosa $(*)$ exists between mucosal carcinoma under which benign glands are present $(* *)$ (scale bar=1200 $\mu m) .(F)$ Type E: a benign regenerative mucosa $(*)$ exists between mucosal carcinoma occupying all mucosal layers $\left.{ }^{* *}\right)$ (scale bar=600 $\left.\mu \mathrm{m}\right)$.

Table III. Predictor variables of submucosal fibrosis of pTla gastric cancers.

\begin{tabular}{|c|c|c|c|c|c|c|}
\hline \multirow[b]{2}{*}{ Characteristics } & \multicolumn{3}{|c|}{ Fibrosis } & \multicolumn{3}{|c|}{ Ulcer scar } \\
\hline & Odds ratio & $95 \% \mathrm{CI}$ & $p$-Value & Odds ratio & $95 \% \mathrm{CI}$ & $p$-Value \\
\hline MLL2 low expression & 5.91 & $1.95-17.9$ & 0.0017 & 5.14 & $1.83-14.5$ & 0.0019 \\
\hline Poorly differentiated histology ("por" and/or "sig") & 8.66 & $2.65-28.3$ & 0.0004 & 4.77 & $1.66-13.7$ & 0.0038 \\
\hline Previous biopsy from cancer & 1.3 & $0.30-5.58$ & 0.722 & 2.98 & $0.52-17.0$ & 0.22 \\
\hline
\end{tabular}

CI: Confidence interval. 


\section{Discussion}

In the present study, MLL2 protein expression was found to be significantly decreased in $15.5 \%$ of gastric cancers examined and its percentage in advanced cancers was consistent with previous findings obtained using nextgeneration sequencing (4). Low expression of MLL2 in advanced cancers was associated with low expression of MSH6, which may increase genomic instability. Although there is currently no information on the relationship between MLL2 and microsatellite instability, a gene mutation in MLL3, a paralogue of MLL2 (18), has been associated with microsatellite instability (19). Furthermore, the relationship between MLL2 and MSH6 was not observed in early cancers, which suggests that the expression of MSH6 protein decreased after that of MLL2 protein.

In the present study, a relationship was observed between low expression of MLL2 and early stage gastric cancers. In pT1a cancers, low expression of MLL2 was associated with submucosal fibrosis, especially ulcer scars. This was an independent relationship that was not confounded by a poorly differentiated morphology or biopsy. In our classification, ulcer scar cancer with low MLL2 expression was classified into type A, type B, or type D. It is thought that there is a close relationship between cancer and fibrosis (20) and that fibrosis occurs before or after carcinogenesis (21). In type A and type $\mathrm{D}(62.5 \%, 10 / 16$ cases $)$, since cancer and fibrosis are not in direct contact with each other, it is more likely that fibrosis developed before cancer, rather than fibrosis caused by cancer. Especially in type D, scar cancer was accompanied by regenerative change. Chronic fibrosis predisposes to cancer initiation (21). During the wound healing response to tissue injury, if the inflammation is prolonged, this process may become a chronic, non-healing wound. Non-healing wound affects epithelial differentiation, epithelial mesenchymal transition, or epithelial cell proliferation, and is thought to contribute to carcinogenesis (20-22). However, in type B, there is a direct contact between cancer and fibrosis. It is considered that type B includes those in which type A cancer cells proliferate in the mucosal full layer and those in which the cancer invades the entire mucosa and induces fibrosis. Indeed, previous studies have reported that the inactivation of MLL2 induced G2/M cell arrest (14), and G2/M cell cycle arrest in epithelial cells resulted in fibrosis (23). Therefore, in type $\mathrm{B}$, a vicious cycle between fibrosis and cancer can be promoted. Type $\mathrm{C}$ and type $\mathrm{E}$ were not observed in the low MLL2 expression group. Type $\mathrm{C}$ with ulcer in the cancer may have been formed by ulceration of the cancer. In type $\mathrm{E}$, where benign regenerative mucosa intervenes in the cancer, it is possible to see regenerative changes after cancer has ulcerated. Considering the above, it is unlikely that fibrosis in scar cancer with low MLL2 expression was caused by an ulcer formed by the cancer.
According to previous reports, most pathogenic mutations of $M L L 2$ gene result in loss of expression or decreased expression of MLL2 protein. However, in this study, we did not investigate the genetic mutations of the MLL2 gene. It should be confirmed in the future whether the results of this study are due to MLL2 gene mutations.

In conclusion, there is a potential association between low expression of MLL2 protein and gastric malignancy from chronic fibrosis.

\section{Conflicts of Interest}

The Authors declare no conflicts of interest. This work was supported by Teikyo University School of Medicine.

\section{Authors' Contributions}

SN was involved in the conceptualization, data analysis and drafted the manuscript. HU acquired the clinicopathological data and provided critical revisions to the manuscript. SN and $\mathrm{HU}$ were involved in the design of the study and performed the scoring of immunohistochemistry. All Authors read and approved the final manuscript.

\section{Acknowledgements}

The Authors are grateful to Masato Watanabe for performing immunohistochemistry on tissue microarray blocks.

\section{References}

1 Kantidakis T, Saponaro M, Mitter R, Horswell S, Kranz A, Boeing S, Aygün O, Kelly GP, Matthews N, Stewart A, Stewart AF and Svejstrup JQ: Mutation of cancer driver MLL2 results in transcription stress and genome instability. Genes Dev 30: 408-420, 2016. PMID: 26883360. DOI: 10.1101/gad.275453.115

2 Froimchuk E, Jang $\mathrm{Y}$ and Ge K: Histone H3 lysine 4 methyltransferase KMT2D. Gene 627: 337-342, 2017. PMID: 28669924. DOI: 10.1016/j.gene.2017.06.056

3 D'Afonseca V, Arencibia AD, Echeverría-Vega A, Cerpa L, Cayún JP, Varela NM, Salazar $M$ and Quiñones LA: Identification of altered genes in gallbladder cancer as potential driver mutations for diagnostic and prognostic purposes: A computational approach. Cancer Inform 19: 1176935120922154, 2020. PMID: 32546937. DOI: 10.1177/1176935120922154

4 Ge S, Li B, Li Y, Li Z, Liu Z, Chen Z, Wu J, Gao J and Shen L: Genomic alterations in advanced gastric cancer endoscopic biopsy samples using targeted next-generation sequencing. Am J Cancer Res 7: 1540-1553, 2017. PMID: 28744403.

5 Ali SM, Sanford EM, Klempner SJ, Rubinson DA, Wang K, Palma NA, Chmielecki J, Yelensky R, Palmer GA, Morosini D, Lipson D, Catenacci DV, Braiteh F, Erlich R, Stephens PJ, Ross JS, Ou SI and Miller VA: Prospective comprehensive genomic profiling of advanced gastric carcinoma cases reveals frequent clinically relevant genomic alterations and new routes for targeted therapies. Oncologist 20: 499-507, 2015. PMID: 25882375. DOI: 10.1634/theoncologist.2014-0378 
6 Rokutan H, Hosoda F, Hama N, Nakamura H, Totoki Y, Furukawa E, Arakawa E, Ohashi S, Urushidate T, Satoh H, Shimizu H, Igarashi K, Yachida S, Katai H, Taniguchi H, Fukayama $\mathrm{M}$ and Shibata T: Comprehensive mutation profiling of mucinous gastric carcinoma. J Pathol 240: 137-148, 2016. PMID: 27313181. DOI: 10.1002/path.4761

7 Xiong W, Deng Z, Tang Y, Deng Z and Li M: Downregulation of KMT2D suppresses proliferation and induces apoptosis of gastric cancer. Biochem Biophys Res Commun 504: 129-136, 2018. PMID: 30177394. DOI: 10.1016/j.bbrc.2018.08.143

8 Hanahan D and Weinberg RA: Hallmarks of cancer: The next generation. Cell 144: 646-674, 2011. PMID: 21376230. DOI: 10.1016/j.cell.2011.02.013

9 Wei Dai YY: Genomic instability and cancer. J Carcinog Mutagen 5: 1000165, 2014. PMID: 25541596. DOI: 10.4172/ 2157-2518.1000165

10 Cancer Genome Atlas Research Network: Comprehensive molecular characterization of gastric adenocarcinoma. Nature 513: 202-209, 2014. PMID: 25079317. DOI: 10.1038/nature13480

11 Mehrotra S and Mittra I: Origin of genome instability and determinants of mutational landscape in cancer cells. Genes (Basel) 11(9): 1101, 2020. PMID: 32967144. DOI: 10.3390/ genes 11091101

12 Sze CC, Ozark PA, Cao K, Ugarenko M, Das S, Wang L, Marshall SA, Rendleman EJ, Ryan CA, Zha D, Douillet D, Chen FX and Shilatifard A: Coordinated regulation of cellular identityassociated $\mathrm{H} 3 \mathrm{~K} 4 \mathrm{me} 3$ breadth by the COMPASS family. Sci Adv 6(26): eaaz4764, 2020. PMID: 32637595. DOI: 10.1126/ sciadv.aaz 4764

13 Numakura S, Uozaki H, Kikuchi Y, Watabe S, Togashi A and Watanabe M: Mesenchymal stem cell marker expression in gastric cancer stroma. Anticancer Res 39: 387-393, 2019. PMID: 30591485. DOI: 10.21873/anticanres.13124

14 Carosso GA, Boukas L, Augustin JJ, Nguyen HN, Winer BL, Cannon GH, Robertson JD, Zhang L, Hansen KD, Goff LA and Bjornsson HT: Precocious neuronal differentiation and disrupted oxygen responses in Kabuki syndrome. JCI Insight 4: e129375, 2019. PMID: 31465303. DOI: 10.1172/jci.insight.129375
15 Aso T, Uozaki H, Morita S, Kumagai A and Watanabe M: Loss of ARID1A, ARID1B, and ARID2 expression during progression of gastric cancer. Anticancer Res 35: 6819-6827, 2015. PMID: 26637902.

16 Tarnawski AS: Cellular and molecular mechanisms of gastrointestinal ulcer healing. Dig Dis Sci 50: S24-33, 2005. PMID: 16184417. DOI: 10.1007/s10620-005-2803-6

17 Yasui A, Ishii J, Kataoka T, Koizumi K, Nishida Y, Shibusawa M, Li Y, Hataya K, Ishii H, Tanaka Y, Mizushima H and Kusama S: "Ikaiyougan ni okeru akusei saikuru setu" (Malignant cycle theory in gastric cancer with ulcer). J Showa Med Assoc 44: 157-162, 1984. DOI: 10.14930/jsma1939.44.157

18 Fagan RJ and Dingwall AK: COMPASS Ascending: Emerging clues regarding the roles of MLL3/KMT2C and MLL2/KMT2D proteins in cancer. Cancer Lett 458: 56-65, 2019. PMID: 31128216. DOI: $10.1016 /$ j.canlet.2019.05.024

19 Watanabe Y, Castoro RJ, Kim HS, North B, Oikawa R, Hiraishi T, Ahmed SS, Chung W, Cho MY, Toyota M, Itoh F, Estecio MRH, Shen L, Jelinek J and Issa JPJ: Frequent alteration of MLL3 frameshift mutations in microsatellite deficient colorectal cancer. PLoS One 6: e23320, 2011. PMID: 21853109. DOI: 10.1371/journal.pone.0023320

20 Rybinski B, Franco-Barraza J and Cukierman E: The wound healing, chronic fibrosis, and cancer progression triad. Physiol Genomics 46: 223-244, 2014. PMID: 24520152. DOI: 10.1152/ physiolgenomics.00158.2013

21 Chandler C, Liu T, Buckanovich R and Coffman LG: The double edge sword of fibrosis in cancer. Transl Res 209: 55-67, 2019. PMID: 30871956. DOI: 10.1016/j.trs1.2019.02.006

22 Gurtner GC, Werner S, Barrandon Y and Longaker MT: Wound repair and regeneration. Nature 453: 314-321, 2008. PMID: 18480812. DOI: $10.1038 /$ nature07039

23 Wynn TA: Fibrosis under arrest. Nat Med 16: 523-525, 2010. PMID: 20448575. DOI: 10.1038/nm0510-523

Received October 27, 2020

Revised November 19, 2020

Accepted November 20, 2020 